Crop Breeding and Applied Biotechnology 16: 35-41, 2016

Brazilian Society of Plant Breeding. Printed in Brazil

\title{
ARTICLE
}

http://dx.doi.org/10.1590/1984-70332016v16n1a6

\section{Tetraploidization in citrus rootstocks: effect of genetic constitution and environment in chromosome duplication}

Divanilde Guerra $^{1,3 *}$, Maria Teresa Schifino-Wittmann², Sérgio Francisco Schwarz ${ }^{1}$, Roberto Luis Weiler ${ }^{2}$, Nair Dahmer ${ }^{2}$ and Paulo Vitor Dutra de Souza ${ }^{1}$

Received 22 February 2015

Accepted 19 October 2015

\begin{abstract}
The objective of this study was to identify polyploid plants from citrus rootstocks and to evaluate the influence of the genetic constitution and of the environment on the frequency of chromosome duplication. Populations obtained from rootstock seeds of Trifoliata [Poncirus trifoliate (L.) Raf], citrumelo 'Swingle' [C. paradise Macf. $\times$ P. trifoliate], citrange 'Troyer' [C. sinensis (L.) Osb. $x$ P. trifoliate] and citranges Fepagro 'C13', 'C37' and 'C41' [C. sinensis (L.) Osb. cv. Pêra $x$ P. trifoliata] were evaluated under field and greenhouse conditions. Flow cytometry analysis of 415 field plants and 435 greenhouse plants identified seven (1.69\%) and $29(6.67 \%)$ tetraploids, respectively. Differences in the number of tetraploid plants among genotypes and locations were observed in field progenies of ' $\mathrm{C} 37$ ' (2.12\%) and 'C 13'(2.04\%) and in greenhouse progenies of 'C 13' (15.52\%) and 'C 37'(6\%). The frequency of autotetraploidization events in citrus rootstocks is common and appears to be associated to genetic constitution and environmental conditions.
\end{abstract}

Key words: Citrus, polyploids, thermal amplitude, protected environment.

\section{INTRODUCTION}

Polyploidy is the existence of three or more sets of chromosomes in the same nucleus. It is of common occurrence in plants, playing an important role in the origin and evolution of plant species (Otto and Whitton 2000). The origin of polyploids can be through unreduced gametes (2n) or through spontaneous duplication of the chromosomes (De Wet 1980, Ramsey and Schemske 1998, Aleza et al. 2011). Polyploids composed of identical sets of chromosomes are referred to as autopolyploid, while the ones formed through interspecific hybridization are allopolyploids (Ramsey and Schemske 1998, Soltis and Soltis 2009).

The majority of species of the Citrus genus are diploids $(2 n=18)$ with a basic number of chromosome $x=9$. However, plants with a different number of chromosomes, such as triploids $(2 n=3 x=27)$ and tetraploids $(2 n=4 x=36)$, are of natural occurrence, originated by both sexual and somatic ways. Polyploids of sexual origin can be obtained through the fusion of an unreduced gamete with a normal haploid or of two unreduced gametes; polyploids of somatic origin, or 'spontaneous polyploids', can appear through natural processes of mutation through the duplication of chromosomes in nucellar cells and the lack of division during mitosis, originating tetraploid plants (Cameron and Frost 1968, Lee 1988, Zeng et al. 2006).

In citrus, tetraploid plants are valuable since crossings with diploid plants can produce triploid varieties that are seedless. They are also of potential interest for the direct use as dwarfing rootstocks (Cameron and Frost 1968, Lee 1988, Ollitrault et al. 2008). The frequency of spontaneous polyploid plants in citrus is variable and appears to be under genetic and environmental control (Barrett and Hutchison 1978, Hussain et al. 2012). However, the factor or factors that influence the frequency of polyploidization events remain unknown, because few studies on the issue have been published.

Studies that seek to identify the factor or factors, like different environments (field and greenhouse), that act in the

\footnotetext{
${ }^{1}$ Universidade Federal do Rio Grande do Sul (UFRGS), Faculdade de Agronomia, Departamento de Horticultura e Silvicultura, Avenida Bento Gonçalves, 7712, 91.501 970, Porto Alegre, RS, Brazil. *Email: divanildeguerra@yahoo.com.br

${ }^{2}$ UFRGS, Faculdade de Agronomia, Departamento de Plantas Forrageiras e Agrometeorologia

${ }^{3}$ Universidade Estadual do Rio Grande do Sul (UERGS), Faculdade de Agronomia, Rua Cipriano Barata, 47, 98.600-000, Três Passos, RS, Brazil
} 
process of polyploidization are new to all rootstocks of this study in Brazil. In addition, in the state of Rio Grande do Sul new rootstocks of citrus named Fepagro were launched, but they haven't been evaluated, and it is very important for the progress of the breeding programs of citrus in the state.

The objectives of this study were: a) to identify polyploid plants in a population obtained through seeds of diploid citrus rootstocks; b) to identify the origin of the polyploid plants; c) to evaluate the influence of the genetic constitution of the rootstocks in the frequency of polyploidization and; d) to evaluate the effect of the rootstock growth environment in the frequency of polyploidization events.

\section{MATERIAL AND METHODS}

For this experiment, mother plants of the following citrus rootstocks were used: trifoliate orange [Poncirus trifoliata (L.) Raf], 'Swingle' citrumelo [C. Paradisi Macf. $\mathrm{x} P$. trifoliata], 'Troyer' citrange [C. sinensis (L.) Osb. $\mathrm{x} P$. trifoliata], and citranges Fepagro 'C13', 'C37' and 'C41' [C. sinensis (L.) Osb. cv. Pêra $\mathrm{x}$ P. trifoliata]. The plants were grown in field and greenhouse conditions, with the exception of ' $\mathrm{C} 41$ ', which was grown only in the greenhouse.

The mother plants grown in the field are located at Fazenda Panoramas Citros, Butiá, RS, Brazil (lat $29^{\circ}$ $57^{\prime} \mathrm{S}$, long $\left.51^{\circ} 40^{\prime} \mathrm{W}\right)$. These plants had already reached maturity (ten years) and were grafted on 'Swingle' citrumelo. They were subjected to natural weather conditions and were fertilized with NPK every 90 days following the technical culture recommendations. The mother plants were grown in a greenhouse at the EEA-UFRGS (Agronomic Experimental Station of the Universidade Federal do Rio Grande do Sul), Eldorado do Sul, RS, Brazil (lat 30 29' S, long $\left.51^{\circ} 06^{\prime} \mathrm{W}\right)$. These plants were also mature, grafted on P. trifoliata, and grown in $100 \mathrm{~L}$ pots containing a mix of soil, decomposed residue of acacia bark and carbonized rice husk (2:2:1-v:v:v). They were grown in a plastic-covered greenhouse (polyethylene $100 \mu \mathrm{m}$ ), of metallic structure, where they were drip-irrigated at a rate of $29.5 \mathrm{~mL}$ minute $^{-1}$ for 10 minutes, three times a day, and fertirrigation with NPK was provided every 15 days (following thetechnical culture recommendations).

Air temperature was monitored through a meteorological station in the field, and a thermohygrograph in the greenhouse. The daily temperature range was calculated for both growth environments (Figure 1).

About a hundred flowers in pre-anthesis were selected randomly on the dates August $25^{\text {th }}$ and $27^{\text {th }}$ and September $2^{\text {nd }}, 9^{\text {th }}, 17^{\text {th }}$ and $19^{\text {th }}$ of 2008 . The dates were numbered from

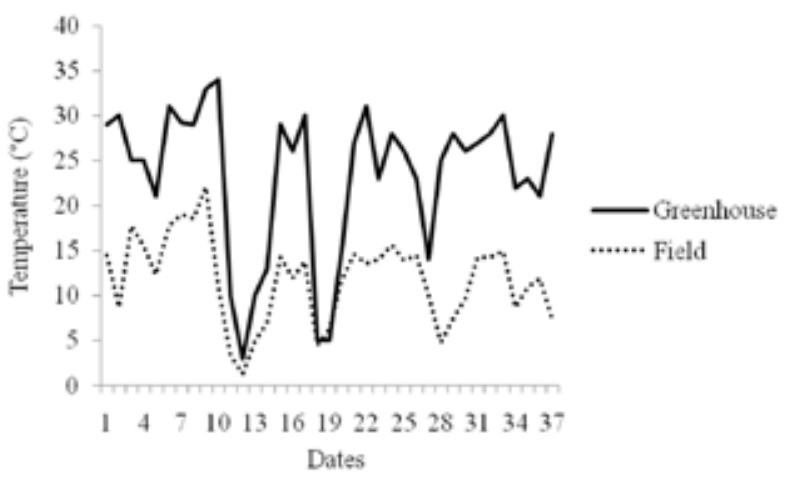

Figure 1. Daily thermal range in the field and greenhouse monitored between August $25^{\text {th }}$ to September $30^{\text {th }}, 2008$.

1 to 6 and the flowers were marked with colored tapes to differentiate each date. Citric plants are perennial and the fruits present a long development cycle from flowering/ fertilization until ripening, thus, the fruit obtained from flowers marked in 2008 were harvested when fully ripe in 2009 , i.e., one year after the flowers were marked.

In 2009, ripe fruits resulting from the flowers marked in 2008 were harvested and identified by each tape color and date of selection. These fruits were washed and disinfested through immersion in ethanol $70 \%$ for 10 minutes, followed by immersion in sodium hypochlorite ( $2 \%$ active ingredient) for five minutes, and then triple washed in autoclaved deionized water. The seeds were collected and disinfested through the same process. In a flux chamber, the external tegument (rusk) and the internal tegument (tegmen) of the seeds were removed. The embryos were carefully separated to avoid damaging or compromising their viability; afterwards the embryos were put to germinate in test tubes containing $30 \mathrm{~mL}$ of MS media (Murashige and Skoog 1962) with a $\mathrm{pH}$ of 6.4. The tubes were kept in controlled environment with a photoperiod of 16 hours and temperature of $25 \pm$ $2{ }^{\circ} \mathrm{C}$ until the plants were $10 \mathrm{~cm}$ tall.

In 2010 , when the plants were $10 \mathrm{~cm}$ tall, these were then transplanted into pots $\left(800 \mathrm{~cm}^{3}\right)$ containing citrus potting media (Rendimax Citrus ${ }^{\circledR}$ - Eucatex ${ }^{\circledR}$ manufacturer). The plants were later acclimatized in a greenhouse in a gradual process (weeks) of contact with the external environment to prevent their death. After the full establishment of plants in the green house (approximately ten months), that is, after developing a fair number of leaves, the plant material required for the ploidy level analysis and possible repetitions was collected.

Flux cytometry was used to determine the ploidy level, using a Cy Flox Ploidy Analyzer (Partec), in IAC (Instituto Agronômico de Campinas) in São Paulo, according to 
methodology described by Aleza et al. (2009). The mother plants that originated the fruit, the population of plants obtained from the flowers selected in 2008 ( 850 plants) and three other plants of known ploidy level (one diploid, one triploid, and one tetraploid), were evaluated. Each sample was composed of a $1 \mathrm{~cm}^{2}$ leaf disk of each plant.

In 2011, the polyploid plants identified by flow cytometry were again transplanted to larger pots $(1200 \mathrm{~cm} 3)$ containing citrus potting medium (Rendimax Citrus ${ }^{\circledR}$ - Eucatex ${ }^{\circledR}$ manufacturer) to obtain roots which were used for the analysis of ploidy level. The polyploid plants had their chromosome number confirmed in 2011 by counting the chromosomes in somatic cells of root tips. The roots were collected, pre-treated with a saturated solution of paradichlorobenzene for $18-20 \mathrm{~h}$ at $4^{\circ} \mathrm{C}$, fixed in 3:1 ethanol-acetic acid for $24 \mathrm{~h}$ and kept in ethanol $70 \%$ in a freezer. The slides were prepared with the root hydrolysis in $\mathrm{HCl} 1 \mathrm{~N}$ at $60^{\circ} \mathrm{C}$ for 10 minutes, stained with Feulgen $(24 \mathrm{~h})$, pre-treated with pectinase $2 \%$, macerated in propionic carmine $2 \%$, and slide and cover slip were further sealed with a resin and beer-wax mix (3:1). At least 10 cells per plant with good chromosome spreading were analyzed. This methodology was adopted since the plants identified as polyploid through the flow cytometry technique could be chimeras, i.e., they presented some polyploid cells while the whole plant was characterized as diploid. Therefore many root tips were necessary for the accurate determination of ploidy level due to the difficulty in scattering and counting of chromosomes; so this step demanded a few months to obtain the necessary material and its characterization. After the total proportions of diploid:polyploid plants in the field and greenhouse (rootstocks combined, except ' $\mathrm{C} 41$ ') were compared statistically using the chi-square test. Further comparisons were performed for each rootstock, (except 'C41'), using the Fisher's Exact Test.

In 2012, after confirming the ploidy level of somatic cells in polyploid plants, we proceeded to confirm their origin, that is, whether they were autotetraploid or allopolyploid, using molecular markers with primers developed and tested by IAC. For molecular analysis, the extraction and quantification of the DNA and the reactions of amplification for the establishment of the molecular profile were prepared according to methodology described by Cristofani-Yaly et al. (2010), using microsatellite molecular markers with starters developed from the sweet orange genome [ $C$. sinensis (L.) Osbeck.] (Table 1). PCR (Polymerase Chain Reaction) was used to amplify specific regions using a PTC100 thermocycler (Programmable Thermal Controller MJ Research, INC) as per methodology described by CristofaniYaly et al. (2010). The product of the PCR was observed in agarose gel of high resolution at $3 \%$. The molecular profile of each plant was established and compared to the genitor plant in all starter combinations.

\section{RESULTS AND DISCUSSIONS}

Eight hundred and fifty plants were evaluated for ploidy level: 415 from the mother plants in the field and 435 from

Table 1. Relation of 18 microsatellite primers used to establish the molecular profile of polyploids and the parental genotypes of citrus rootstocks

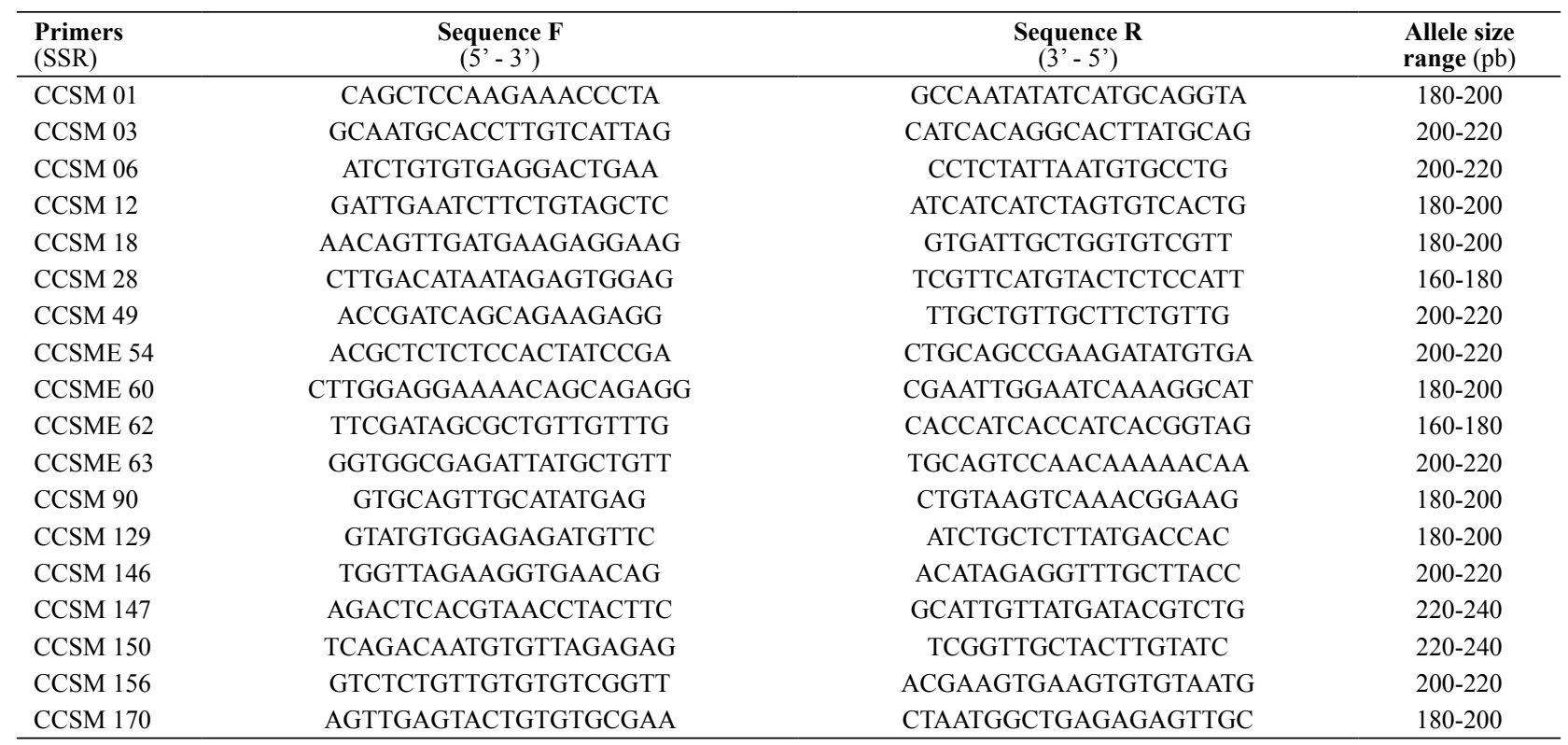


mother plants in the greenhouse (Table 2), which allowed the identification of 36 polyploid plants (Figure 2). According to Ramsey and Schemske (1998), somatic duplication in young embryos can occur in parts of the plant, generating mixoploid chimeras, which according to Aleza et al. (2011) is common in citrus. However, the hypothesis of mixoploid portions in the leaves was discarded by chromosome counting. By counting the chromosomes, the plants were also identified as being tetraploids $(2 \mathrm{n}=36)$ (Figure 2$)$.

In this study, from the 415 plants obtained from the fieldgrown mother plants, 408 (98.31\%) were diploid $(2 n=18)$ and seven $(1.69 \%)$ tetraploid $(2 n=36)$; while from the 435 plants obtained from greenhouse-growing mother plants, $406(93.33 \%)$ were diploid and $29(6.67 \%)$ tetraploid (Table $2)$. The percentages of polyploid plants identified in this study are in agreement with what was proposed by Barrett and Hutchison (1978) and Saleh et al. (2008), for whom the percentage of polyploid plants in citrus is below $11 \%$, as well as the affirmation by Aleza et al. (2011) that the natural polyploidization events in citrus are common, but occur in low frequencies.

According to Otto and Whitton (2000), the polyploidy formation rate appears to vary with environmental conditions. For Saleh et al. (2008), Aleza et al. (2011), and Hussain et al. (2011), the frequency of tetraploidization events in citrus

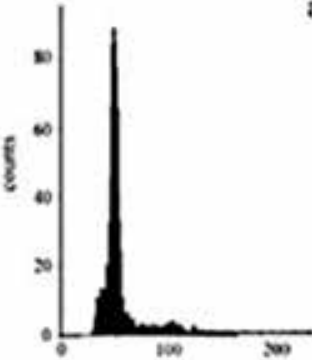

a
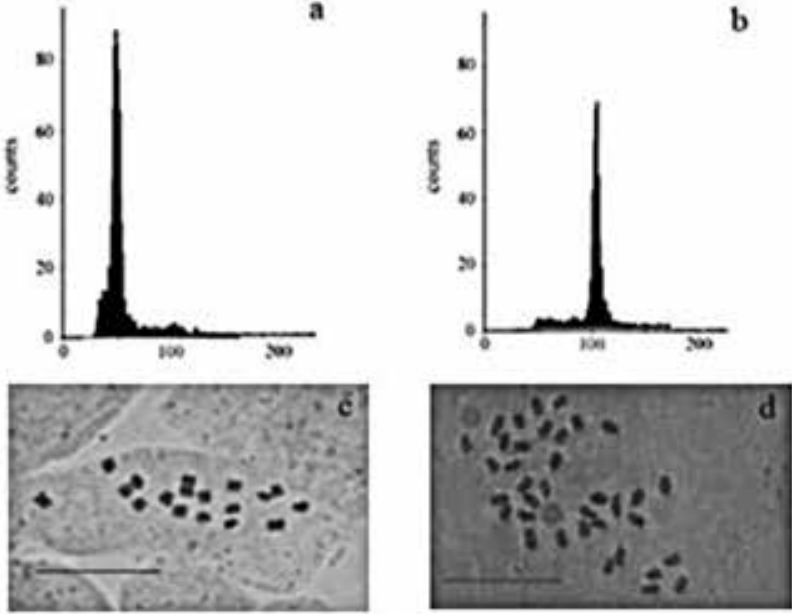

Figure 2. Result of ploidy level determination by flux cytometry and chromosome count in somatic cells of citrus rootstocks conducted in greenhouse. a) Diploid parent plant of Citrange Fepagro 'C 13'; b) Tetraploid progeny resulting from Citrange Fepagro 'C 13'; c) Diploid plant parent $(2 n=18)$ of Citrange Fepagro ' $\mathrm{C} 13$ '; $\mathrm{d})$ Tetraploid progeny $(2 \mathrm{n}=36)$ resulting from Citrange Fepagro 'C 13'; Scale $10 \mu \mathrm{m}$.

is dependent of the environment where plants are grown. In this study, differences in polyploid percentage were observed for the two growth environments, with $1.69 \%$ of tetraploid plants in the field and $6.66 \%$ in the greenhouse

Table 2. Result of ploidy level analysis of the citrus rootstocks plants obtained from fruit seeds of the flowers that were marked in the field and greenhouse in 2008

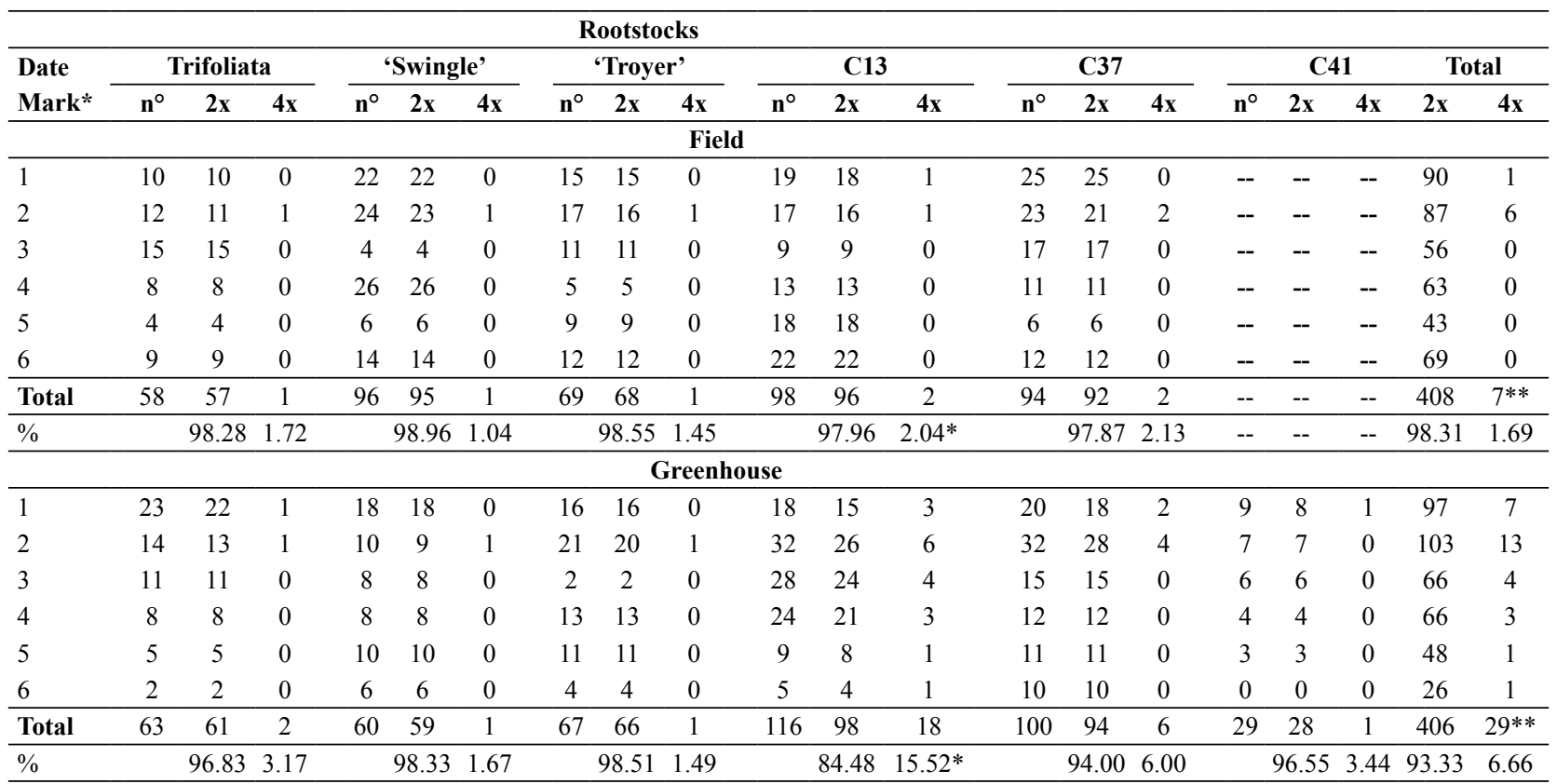

*Date Mark= Dates when flowers were marked: 1 (August, 25), 2 (August, 27) 3 (September, 02), 4 (September, 09), 5 (September, 17), 6 (September, 19); ${ }^{\circ}=$ number of plants; $2 \mathrm{x}=$ plant diploid; $4 \mathrm{x}=$ plant tetraploid; Total $=$ total of plants evaluated; $\%=$ percentage of plants evaluated, diploids ortetraploids. ${ }^{*}=$ Significant at $5 \%$ probability by Fisher's Exact Test; ** = Significant at $5 \%$ probability by the chi-square test. 
(Table 3). The proportion of rootstocks (except ' $\mathrm{C} 41$ ') grown in greenhouse showed $6.88 \%$ of polyploid plants and the rootstocks conducted in field $1.69 \%$, significantly different (

$$
(X 2-12.401, \mathrm{df}=1, \mathrm{p}-\text { value }=0.000429) .
$$

These results are in agreement with the hypothesis by Otto and Whitton (2000), Saleh et al. (2008), Aleza et al. (2011), and Hussain et al. (2011), that different environmental conditions such as temperature can have an effect on the events of chromosome duplication. The results in this study also match those of Barret and Hutchison (1978), who identified $0.75 \%$ and $0.90 \%$ of polyploid plants in fruits harvested in Florida and California, respectively, and associated the difference to temperature. In the field, the majority of polyploid plants were identified in the progeny of the citranges ' $\mathrm{C} 37$ ' (2.12\%) and ' $\mathrm{C} 13$ ' (2.04\%), while in the greenhouse it was in the citranges ' $\mathrm{C} 13$ ' (15.52\%) and ' $\mathrm{C} 37$ ' (6.00\%) (Table 2). However, when comparing within each genotype in different environments, there was only a significant difference with rootstock ' $\mathrm{C} 13$ '. Therefore, the differences observed are associated to distinct genetic constitutions and thermal amplitude, as well as the hybrid origin of the genotypes. The distinct genetic constitution is considered one of the factors influencing the percentage of chromosome duplication in citrus (Barrett and Hutchison 1978, Saleh et al. 2008, Aleza et al. 2012). Barret and Hutchison (1978) obtained $0.2 \%$ of chromosome-duplicated plants in rough lemon (C. jambhiri) and 3.3\% in 'Key' lime $(C$. aurantifolia) grown in the same environmental conditions. Saleh et al. (2008) observed variation in the polyploidy percentages of plants in P. trifoliata (5.4\%); 'Carrizo' citrange $(C$. sinensis $\times P$. trifoliata) $(7 \%)$ and 'Cleópatra' tangerine (C. reshni Hort.) (4\%). Aleza et al. (2011) found variations among the genotypes: $C$. sinensis $(0.8 \%)$; C. paradisi $(2.8 \%)$; C. reticulata $(3.0 \%)$; and the hybrids $C$. reticulata $\times C$. sinensis $(3.5 \%)$, and C. reticulata $\times$ C. paradisi (2.5\%). Therefore, the differences observed in the percentage of tetraploid plants among the different rootstocks in this study (Table 2) allow us to conclude that the genetic constitution favors the tetraploidization of some genotypes.

The hybrid origin of genotypes can favor the polyploidization. According to Machado et al. (2005), the interspecific hybridization can contribute to the frequency of polyploids in citrus. Therefore, the highest percentage of autopolyploid plants identified in the rootstock mother plants in this study (Table 2) could be associated to the hybrid origin of the plants. Barrett and Hutchison (1978) also found increased frequency of tetraploid plants in hybrids, when studying 42 populations of Citrus, Poncirus and

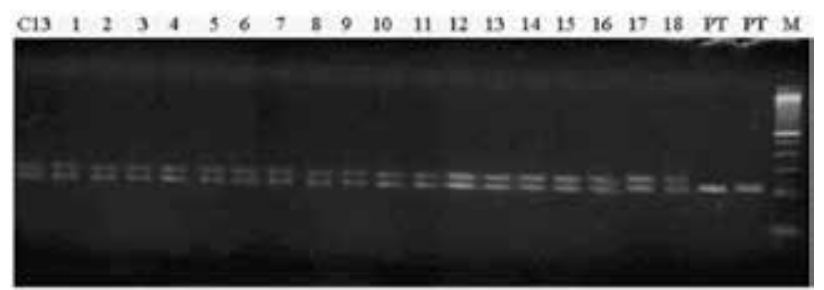

Figure 3. Amplified fragments of DNA using microsatellite primer CCSM 06 in some plants of the population evaluated. $\mathrm{C} 13=$ Citrange Fepagro ' $\mathrm{C}$ 13 ' (parent); 1 to $18=$ Progeny obtained from citrange Fepagro 'C 13'; $\mathrm{PT}=$ trifoliata; $\mathrm{M}=$ Molecular marker.

hybrids. The results of the present study also confirm the hypothesis of Otto and Whitton (2000), in which the rate of formation of polyploids in plants appears to vary with genetic constitution and the hybrid or non-hybrid origin of the material.

In relation to the dates of selection, greatest percentages of polyploid plants were observed in flowers in pre-anthesis in the earlier dates. In the field, the first date resulted in one polyploid plant, the second six plants, and in the third, fifth and sixth dates no polyploid plants were identified. In the greenhouse, in the first date, seven polyploid plants were obtained; in the second 13 plants; third and fourth, four and three plants, respectively; and in the fifth and sixth one plant each (Table 2).

The differences in polyploidization percentages observed in this study can be associated to the differences in environmental factors in the distinct dates of flower selection (Table 2). According to Thakur et al. (2010), in several species the temperature stress results in irreversible damages to the male and female reproductive systems of plants. Low temperatures are suggested as one of the factors that influence polyploidization in citrus. Aleza et al. (2011) observed higher percentages of tetraploid seedlings from fruits of the 'Carrizo' citrange [C. sinensis x P. trifoliata] rootstock harvested from cold regions. The authors found polyploidization percentages of $12.1 \%$ in Corsica; $8.8 \%$ in California; $19.2 \%$ in Valencia; $13.3 \%$ in Uruguay; $6.2 \%$ in South Africa; $2.5 \%$ in Florida; $1.9 \%$ in São Paulo; and $0.9 \%$ in Bahia. However, the results obtained in the present study regarding the frequency of polyploid plants (Table 2) do not agree with the hypothesis suggested by Aleza et al. (2011) that the low temperatures result in increased duplication of chromosomes. In this study, the minimum temperature in both growth environments was similar (1.3 ${ }^{\circ} \mathrm{C}$ in the field and $3.0^{\circ} \mathrm{C}$ in greenhouse), but the maximum temperature was different $\left(22.04{ }^{\circ} \mathrm{C}\right.$ in the field and 34.0 ${ }^{\circ} \mathrm{C}$ in greenhouse), with higher thermal amplitude in the greenhouse (Figure 1). This allows us to infer that this 
variation in amplitude influences the ploidy level of the evaluated seedlings, but it is not possible, however, to identify the exact factor, or factors, that resulted in polyploidization. Guerra et al. (2013) suggested thermal amplitude as the likely factor that changed the male fertility in the same mother plants used in this study; those authors observed a lower percentage of normal meiotic cells and lower viability and in vitro germination of pollen grains in the plants grown in greenhouse compared to the field. Therefore, some factor present in the greenhouse conditions, like temperature and thermal amplitude, damaged the male fertility and could be promoting the polyploidization of plants in this environment.

The molecular profiles of the tetraploid plants and the mother plants were established using 18 microsatellites primers (Table 1). This revealed the pattern of bands followed by the tetraploid plants and their respective genitor in all combinations of primers; this result can be observed in Figure 3, which represents some plants of the population evaluated. With these results, it can be concluded that the origin of all polyploid plants in this study is resultant of the somatic duplication of nucellar cells, followed by the lack of division of these during the mitosis. These are characterized as being 'spontaneous polyploids', or autopolyploid, for being genetically identical to the mother plant. This result is in accordance to those obtained by Zeng et al. (2006), Allario et al. (2011) and Hussain et al. (2011). In this study, the use of microsatellite markers was efficient in identifying the molecular profile of the tetraploid plants. Good results with this technique were also obtained by Saleh et al. (2008), using five microsatellite starters to compare tetraploid and

\section{REFERENCES}

Aleza P, Juárez J, Ollitrault P and Navarro L (2009) Production of tetraploid plants of non apomictic citrus genotypes. Plant Cell Reports 28:1837-1846.

Aleza P, Froelicher Y, Schwarz S, Agusti M, Hernández M, Juárez J, Luro F, Morillon R, Navarro L and Ollitrault P (2011) Tetraploidization events by chromosome doubling of nucellar cells are frequent in apomictic citrus and are dependent on genotype and environment. Annals of Botany 108: 37-50.

Aleza P, Juárez J, Hernández M, Ollitrault P and Navarro L (2012) Implementation of extensive citrus triploid breeding programs based on $4 x \times 2 x$ sexual hybridization. Tree Genetics \& Genomes 8: $1293-1306$

Allario T, Brumos J, Colmenero-Flores JM, Tadeo F, Froelicher Y, Talon M, Navarro L and Morillon R (2011) Large changes in anatomy and physiology between diploid Rangpur lime (Citrus limonia) and its autotetraploid are not associated with large changes in leaf gene expression. Journal of Experimental Botany 62: 2507-2519. diploid seedlings of $P$. trifoliata, 'Carrizo' citrange [C. sinensis $\times P$. trifoliata $]$ and 'Cleópatra' tangerine $(C$. reshni $)$; by Allario et al. (2011), using 10 microsatellite starters to establish the molecular profile of diploid and tetraploid plants of 'Rangpur' lime (C. limonia); and by Aleza et al. (2011), evaluating 80 tetraploid plants of 30 citrus genotypes with 24 microsatellite starters to establish the molecular profile and compare them to the diploid parents. In the studies by Saleh et al. (2008), Allario et al. (2011) and Aleza et al. (2011), as in the present study, the molecular profile of the tetraploid plants was identical to the diploid parents, that is, all markers were monomorphic, proving that the polyploid genotypes are due to the duplication of the chromosome set of diploid somatic cells.

\section{CONCLUSIONS}

Thirty-six polyploid plants of citrus rootstocks were identified and characterized as autotetraploid originated via somatic chromosome duplication. Autopolyploidization events in citrus are associated to the genetic constitution of genotypes and are influenced by the growth environment of the plants.

\section{ACKNOWLEDGMENTS}

To CAPES (Coordenação de Aperfeiçoamento de Pessoal de Nível Superior, Brazil) and CNPq (Conselho Nacional de Desenvolvimento Científico e Tecnológico, Brazil) for the funding. A special thanks to Dr. Miguel Dall'Agnol for the use of the molecular analysis lab and Dr. Marcos Machado for the use of the Flux Cytometry Analysis lab at IAC.

Barrett HC and Hutchison DJ (1978) Spontaneous tetraploidy in apomictic seedlings of Citrus. Economic Botany 32: 27-45.

Cameron JW and Frost HB (1968) Genetics, breeding, and nucellar embryony. In Reuther W, Batchelor LD and Webber HJ (eds) The citrus industry. Berkeley, University of California, p.325-370.

Cristofani-Yaly M, Novelli VM, Bastianel M and Machado MA (2010) Transferability and level of heterozygosity of microsatellite markers in citrus species. Plant Molecular Biology Reporter 29: 418-423.

De Wet JMJ (1980) Origins of polyploids.In Lewis WH (ed) Polyploidy: biological relevance. Plenum, New York, p.3-15.

Guerra D, Schifino-Wittmann MT, Schwarz SF, Souza PV and Campos SS (2013) Reproductive characteristics of citrus rootstocks grown under greenhouse and field environments. Crop Breeding and Applied Biotechnology 13: 186-193.

Hussain S, Curk F, Ollitrault P, Morillon R and Luro F (2011) Facultative apomixis and chromosome doubling are sources of heterogeneity in citrus rootstock trials: Impact on clementine production and breeding selection. Scientia Horticulturae 130: 815-819. 
Hussain S, Curk F, Dhuique-Mayer C, Urban L, Ollitrault P, Luro F and Morillon F (2012) Autotetraploid trifoliate orange (Poncirus trifoliata) rootstocks do not impact clementine quality but reduce fruit yields and highly modify rootstock/scion physiology. Scientia Horticulturae 134: 100-107.

Lee LS (1988) Citrus polyploidy - origins and potential for cultivar improvement. Australian Journal of Agricultural Research 39: 735-747.

Machado MA, Cristofani-Yaly M, Amaral AM and Oliveira AC (2005) Genética, melhoramento e biotecnologia de citros. In Mattos Junior D, De Negre JD, Pio RM and Pompeu Junior J (eds) Citros. Instituto Agronômico e Fundag, Campinas, p.221-277.

Murashige T and Skoog F (1962) A revised medium for rapid grow than bioassays with tobacco cultures. Physiology Plant 15: 473-497.

Ollitrault P, Dambier D, Luro F and Froelicher Y (2008) Ploidy manipulation for breeding seedless triploid citrus. Plant Breeding Reviews 20: 323-354.
Otto SP and Whitton J (2000) Polyploid incidence and evolution. Annual Review of Genetics 34: 401-437.

Ramsey J and Schemske DW (1998) Pathways, mechanisms, and rates of polyploidy formation in flowering plants. Annual Review of Ecology and Systematics 29: 467-501.

Saleh B, Allario T, Dambier D, Ollitrault P and Morillon R (2008) Tetraploid citrus rootstocks are more tolerant to salt stress than diploid. Compets Rendus Biologies 331: 703-710.

Soltis PS and Soltis DE (2009) The role of hybridization in plant speciation. Annual Review of Plant Biology 60: 561-588.

Thakur P, Kumar S, Malik JA, Berger JD and Nayyar H (2010) Cold stress effects on reproductive development in grain crops: An overview. Environmental and Experimental Botany 67: 429-443.

Zeng SH, Chen CW, Hong L, Liu JH and Deng XX (2006) In vitro induction, regeneration and analysis of autotetraploids derived from protoplasts and callus treated with colchicine in Citrus. Plant Cell, Tissue and Organ Culture 87: 85-93. 